\title{
Surgical excision of ectopic hepatic tissue in the right atrium
}

\author{
Suresh Giritharan, MBChB, MRCS(Ed), Kareem Salhiyyah, MRCS(Ed), MSc, PhD, and \\ Geoffrey Tsang, MD, FRCS (CTh), Southampton, United Kingdom
}

\author{
From the Wessex Cardiothoracic Centre, University Hospitals Southampton, Southampton, United Kingdom. \\ Disclosures: Authors have nothing to disclose with regard to commercial support. \\ Received for publication April 11, 2017; revisions received July 3, 2017; accepted for publication July 24, 2017; \\ available ahead of print Sept 22, 2017. \\ Address for reprints: Suresh Giritharan, MBChB, MRCS(Ed), Wessex Cardiothoracic Centre, University Hospi- \\ tals Southampton, Tremona Rd, Southampton SO16 6YD, United Kingdom (E-mail: suresh.giritharan@gmail. \\ com). \\ J Thorac Cardiovasc Surg 2018;155:e47-8 \\ $0022-5223 / \$ 36.00$ \\ Crown Copyright (c) 2017 Published by Elsevier Inc. on behalf of The American Association for Thoracic Surgery \\ http://dx.doi.org/10.1016/j.jtcvs.2017.07.080
}

Video clip is available online.

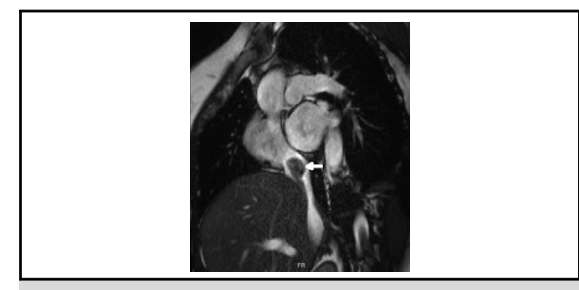

MRI showing ectopic liver mass at the junction of the IVC and right atrium with connecting stalk.

Central Message

Intracardiac or intracaval presence of ectopic liver tissue is rare and can be easily misdiagnosed. A high index of suspicion and good images with MRI help guide surgical excision.

See Editorial Commentary page e49.
Heterotopic hepatic tissue is uncommon, usually found surrounding the gallbladder and other intra-abdominal organs. Intracardiac liver tissue is extremely rare, often misdiagnosed as a myxoma or thrombus. ${ }^{1}$ We describe a case of ectopic liver mass found at the junction of the inferior vena cava (IVC) and the right atrium, which was excised surgically, focusing on points of diagnosis and surgical strategy.

\section{CASE REPORT}

A 30-year-old woman presented with central chest pain, nonspecific electrocardiogram changes, and normal cardiac enzymes. The patient's medical history included endometriosis, cholecystectomy, and 5 normal pregnancies. Her body mass index (BMI) was $34 \mathrm{~kg} / \mathrm{m}^{2}$. Transthoracic echocardiography showed a $2.3 \times 1.2-\mathrm{cm}$ mass in the right atrium (Video 1), initially thought to be a thrombus, and she was anticoagulated. A magnetic resonance imaging (MRI) scan showed a point of attachment of the mass to the IVC as it passed over the diaphragm. The lesion had low-tointermediate $\mathrm{T} 1$ signals similar to myocardium.

The operative approach was via a sternotomy. Because unobscured access to the IVC was necessary for excision, venous return for cardiopulmonary bypass (CPB) was established by cannulation of the right femoral vein and superior vena cava. Moderate hypothermia $\left(32^{\circ} \mathrm{C}\right)$ was maintained, the heart was arrested using antegrade cardioplegia, and both cavae were snared. The right atrium was opened, and an oval-shaped muscular mass was identified, attached to the wall of the IVC by a stalk arising just above the portal veins. CPB flow was reduced intermittently for resection of the mass. The stalk was cauterized close to its base without incident.

Histology demonstrated a polypoid mass of normal liver parenchyma with portal tracts with focal fatty change of the hepatocytes without any evidence of granulomatous inflammation, necrosis, or malignancy. There was no evidence of myocardial, atrial, or venous tissue.

\section{COMMENT}

Heterotrophic liver tissue is classified as aberrant or ectopic on the basis of blood supply; the latter does not receive blood supply from the hepatic artery. There are approximately 120 documented cases of heterotrophic liver tissue, and only 6 were reported to be intracardiac/caval. Several theories were proposed to explain their cause, including an embryologic anomaly given the close relationship of the primitive liver bud, the septum transversum, and the IVC. ${ }^{2}$ Previous cases showed a predilection toward young women with a high BMI, which may suggest an association.

In all cases of intracardiac/caval heterotropic liver tissue, the intervention of choice has been surgical excision via sternotomy and CPB. ${ }^{3-5}$ Should the mass be positioned in such a way that hinders adequate flows on CPB, an alternative operative approach with deep hypothermic circulatory arrest may be used.

The technique of using electrocautery for removal of the mass must be used with caution; the risk of IVC injury with this method is not insignificant, especially because complete resection of such a mass is warranted. The surgical team should be prepared with a strategy for IVC repair 


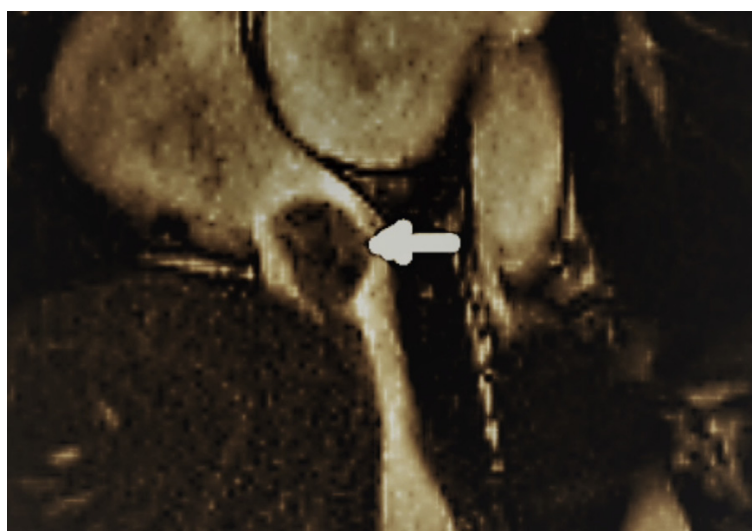

VIDEO 1. Echocardiogram demonstrating a mass at the junction of the IVC and right atrium. Video available at: http://www.jtcvsonline.org/ article/S0022-5223(17)31776-2/fulltext.

should it be required. We would recommend direct repair of an IVC injury with an elliptical resection around the area of injury and direct repair with a bovine pericardial patch (for an injury to the posterior wall of the IVC, a pericardial patch repair would require access through the anterior IVC wall to facilitate repair of the posterior defect as mentioned, and a subsequent patch repair to the iatrogenic anterior wall defect). The option of endovascular techniques (ie, snaring or ablation) has been considered in other case reports, but the initial diagnostic doubt remains the decisive factor in selecting the therapeutic approach.

MRI was essential in obtaining an accurate preoperative diagnosis by triangulating the exact position of the mass and its adjacent anatomic relations, which helped in the surgical planning and cannulation strategy. It also ruled out the presence of other cardiac lesions or anomalies. Current departmental practice is for patients to undergo MRI scanning only if follow-up echocardiography shows no resolution of the mass after anticoagulation; however, this experience along with a review of the literature would suggest that it is not unreasonable to consider an MRI scan at first presentation in young women of childbearing age with an increased BMI, because this can prevent diagnostic delay and potential unwanted sequelae.

\section{CONCLUSIONS}

Heterotrophic liver tissue is a rare but important differential in the diagnosis of an intracardiac mass, particularly on the right side. MRI is essential for accurate diagnosis and to guide surgical resection. The relationship with obesity and female gender suggest potential hormonal factors.

\section{References}

1. Ansari-Gilani K, Jenkins T, Landeras L, Xin W, Rajiah P. Multimodality imaging of an unusual case of an obstructive intracaval mass by an aberrant liver. Circulation. 2014;129:310-2.

2. Kogure K, Ishizaki M, Nemoto M, Kuwano H, Yorifuji H, Ishikawa H, et al. Close relation between the inferior vena cava ligament and the caudate lobe in the human liver. J Hepatobiliary Pancreat Surg. 2007;14:297-301.

3. Trocciola SM, Balsam LB, Yee H, Gianos E, Srichai MB, DeAnda A Jr. Ectopic liver: an unexpected finding in a right atrial mass. Ann Thorac Surg. 2011;92: 715-8.

4. Xu L, Jeudy J, Burke AP. Ectopic hepatic tissue presenting as right atrial mass. Hum Pathol. 2012;43:958-60.

5. Sarsam S, Arsene C, Abu-Rashed K, Liu Q, Rajagopal R. Heterotopic hepatic polyp identified in the right atrium. J Med Cases. 2012;3:274-6. 